\title{
latrogenic causes of hilar radiopaque densities
}

\section{To the Editors:}

We read with interest the case by VANDOOREN et al. [1], which highlighted one unusual cause of iatrogenic lung hilar densities. Embolisation of cement following percutaneous application and, indeed, embolisation of other foreign material (for example, cyanoacrylate glue and sclerotherapy agents) following endoscopic injection of gastric or oesophageal varices is well recognised [2].

We recently described the novel management of postpneumonectomy empyema with bronchopleural fistula using bronchoscopic glue injection [3, 4]. Cyanoacrylate glue is mixed with lipiodol for endobronchial injections into the submucosal layer of the proximal end of the bronchopleural fistula, raising the mucosa and thereby reducing the diameter of the fistula. The success rate of bronchoscopic closure of postlung-resectional bronchopleural fistula $(<0.5 \mathrm{~cm}$ in diameter) using this technique in selected patients was $83 \%$ [3]. The

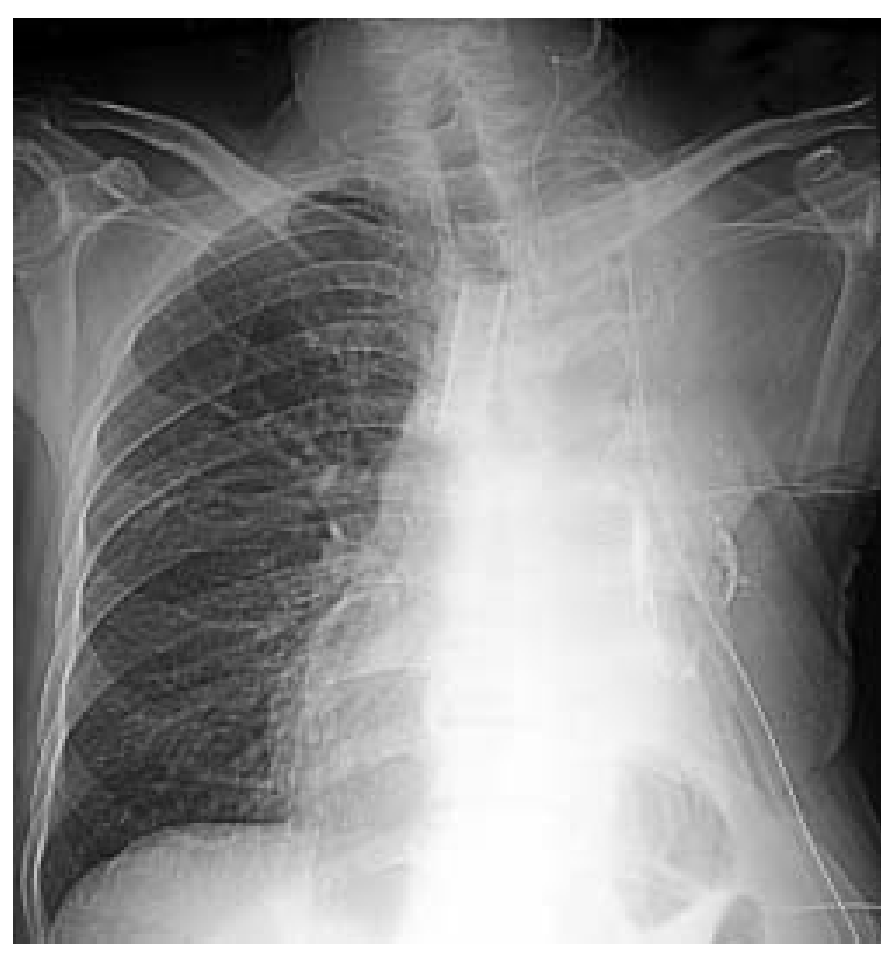

FIGURE 1. Chest radiograph.

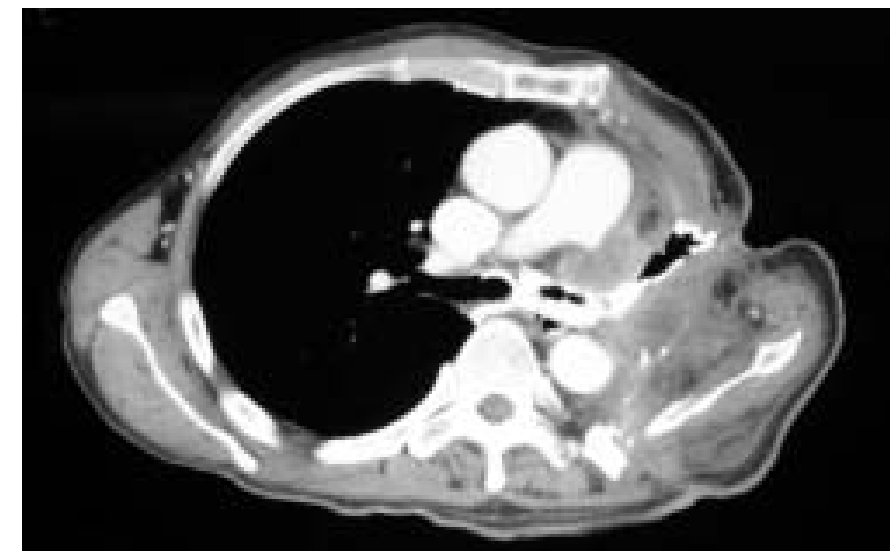

FIGURE 2. Chest computed tomography scan.

images shown (figs 1 and 2) are from a 62-yr-old male with left post-pneumonectomy bronchopleural fistula treated with glue and lipiodol injections, and Dumon stent to the right main bronchus, after failed surgical repair of the fistula. The radiopaque lipiodal glue mixture is occluding the left bronchopleural fistula with spillage into the left pleural cavity, which highlights the muscle transposition flap. Clinicians should be aware of this form of bronchoscopic therapy, and recognise it as another cause of iatrogenic hilar radiopaque densities.

\section{C.S.H. Ng, T.W. Lee and A.P.C. Yim}

Dept of Surgery, The Chinese University of Hong Kong, Shatin, Hong Kong.

\section{REFERENCES}

1 Vandooren B, Haenebalcke C, Bogaerts Y. Two patients with the same type of iatrogenic disease. Eur Respir J 2005; 25: 389-391.

2 Rickman OB, Utz JP, Aughenbaugh GL, Gostout CJ. Pulmonary embolization of 2-octyl cyanoacrylate after endoscopic injection therapy for gastric variceal bleeding. Mayo Clin Proc 2004; 79: 1455-1458.

$3 \mathrm{Ng} \mathrm{CSH}$, Wan S, Lee TW, Wan IYP, Arifi AA, Yim APC. Postpneumonectomy empyema: current management strategies. ANZ J Surg 2005; (In press).

4 Yim APC. Paradigm shift in empyema management. Chest 1999; 115: 611-612. 